\title{
HAWTHORNE ENTRE PURITANISMO E TRANSCENDENTALISMO
}

Geraldo Magela Cáffaro (UFMG)

A preocupação moral e religiosa ocupa lugar de destaque na obra do escritor americano Nathaniel Hawthorne. Essa característica tem sido a principal norteadora da crítica do escritor, levando a abordagens muitas vezes reducionistas de sua escrita. Assim, a tendência mais comum tem sido, até agora, ler Hawthorne como um mero defensor dos ideais puritanos. Tal tendência mostra-se reducionista na medida em que negligencia a influência de uma outra corrente de pensamento na obra do escritor: o transcendentalismo.

Se por um lado, para Hawthorne o puritanismo representava a ancestralidade e a tradição, por outro, o transcendentalismo era a possibilidade de renovação de valores morais e individuais. Dessa forma, percebe-se que Hawthorne vivia entre dois mundos, ora flertando com o passado (puritanismo), ora com o futuro (transcendentalismo). Essa posição lhe permitiu, muitas vezes, agir como observador e crítico de ambos os lados.

Nos contos "O Artista do Belo" e a "A Imagem de madeira de Drowne", Hawthorne revela seu lado progressista e assume a postura de crítico do puritanismo ou, como sugere Stuart Pratt Sherman, "um crítico do puritanismo sob o ponto de vista transcendentalista". ${ }^{1}$ Essa postura pode ser confirmada através da análise de pontos divergentes entre as duas escolas de pensamento com relação ao tema da criação.

A relevância desse tema reside nas suas várias implicações sob a perspectiva bíblica do Gênesis, entre as quais cito o pecado da soberba ou orgulho, a doutrina do pecado herdado e a visão da mulher como ameaça à moral. De acordo com alguns críticos, Hawthorne compartilhava desses princípios puritanos. Heather O’Toole,

\footnotetext{
${ }^{1}$ Citado por MILLS, 1948, p. 72: “[...]a subtle critic and satirist of Puritanism from the transcendental point of view." Tradução minha.
} 
por exemplo, afirma que o "escritor acreditava que na essência da alma individual há algum mal inato, alguma degeneração profunda que impede qualquer pessoa de alcançar bondade real". ${ }^{2}$ Em contrapartida, A. W. Ward et al. ${ }^{3}$ reconhecem a influência de Emerson sobre Hawthorne e apontam a adoção dos ideias transcendentalistas da superalma "over-soul" e da auto-confiança "self-reliance" pelo escritor. Nos contos selecionados para essa análise, esses ideais constituem uma oposição aos princípios do orgulho e do mal inato, o que confirma a posição de Hawthorne como crítico do puritanismo.

Em "O Artista do Belo,"4 dois personagens antagonistas (Owen Warland e Peter Hovenden) representam o choque de valores entre as duas linhas de pensamento. Owen é o inventor romântico que busca "dar forma ao espírito do Belo", 5 conferindo vida à réplica mecânica de uma borboleta. Peter Hovenden, antigo mestre de Owen, pelo contrário, é um homem prático que sempre cultivou o utilitarismo e se opõe aos experimentos de seu ex-aluno.

Sob uma perspectiva puritana, a determinação do inventor de materializar o espírito do Belo é absolutamente condenável. De fato, em termos religiosos, somente Deus é capaz de conferir vida às criaturas. Por isso, ao tentar emular Deus, Owen estaria cometendo o pecado do orgulho. Em vista disso, Peter Hovenden assume a posição de seu julgador, representando a abordagem puritana da criação e, ao ver o projeto incompleto da borboleta, acusa o jovem de bruxaria e o ameaça de exorcismo.

Em contraste com essa abordagem, Emerson defende, de acordo com o ideal do "self-reliance", que o "homem deve viver de acordo com sua natureza, ouvindo os ditames da superalma revelados em seus impulsos; para isso, ele deve se

\footnotetext{
${ }^{2}$ O'TOOLE. "[...] at the core of every individual's soul there is some innate evil, some deep down rottenness which prevents any person from achieving absolute, genuine goodness." Tradução minha.

${ }^{3}$ WARD, 2000.

${ }^{4}$ HAWTHORNE, 1982, p. 907-932.

5 Ibidem. “ [...] putting the spirit of beauty into form." Tradução minha.
} 
manter livre do passado, e das convenções da sociedade...." ${ }^{6}$ Tal premissa encontra paralelo em “O Artista do Belo”, como confirma o trecho a seguir:

É necessário que o artista ideal possua a força de caráter que é dificilmente compatível com sua delicadeza; ele deve manter a fé em si mesmo, enquanto o mundo incrédulo o ataca com sua total descrença; ele deve se defender contra a humanidade e ser seu único discípulo, tanto no que diz respeito a gênio quanto aos objetos para o qual ele é dirigido.

Assim, considerando-se a influência do pensamento de Emerson sobre Hawthorne, o ideal do "self-reliance" isentaria Owen do pecado do orgulho.

Similarmente, o conceito transcendentalista da "over-soul" constitui oposição à noção puritana de mal herdado. Em "Spiritual Laws” Emerson define a "over-soul” como “... o espírito que está no centro da natureza, e sobre a vontade do homem, de forma que nenhum de nós pode fazer mal ao universo". 8 É esse espírito que leva Owen a criar sua própria versão do Belo, e não sua propensão para o mal. De fato, como comenta o narrador, "Ele sabia que o mundo, e Annie como representante do mundo, [...] nunca poderiam dizer a palavra apropriada, nem manifestar o sentimento exato que seriam a recompensa perfeita para o artista que, simbolizando uma moral superior através de uma materialidade trivial convertendo o que era terreno, a ouro espiritual - tinha alcançado o Belo em seu artesanato."9

Além dos ideais transcendentalistas, a representação das personagens femininas fornece um outro exemplo de crítica à crença puritana. Em "O Artista do Belo," Annie Hovenden é a única pessoa a apoiar Owen desde o início e é, de fato, sua maior motivação para dar vida ao projeto do Belo. Assim, a representação de Annie ilustra o comentário de Bárbara Ellis sobre as mulheres de Hawthorne, de

\footnotetext{
${ }^{6}$ Citado por WARD, 2000: “[...] man should live according to his own nature, by listening to the dictates of the over-soul as revealed in his impulses; to this end he should keep himself free of the imprisoning past, and of conventional society, [...]." Tradução minha.

${ }^{7}$ HAWTHORNE, 1982, p. 913.

${ }^{8}$ EMERSON, 1950, p. 97.

${ }^{9}$ HAWTHORNE, 1982, p. 928: “[...] He knew that the world, and Annie as the presentative of the world, [...] could never say the fitting word, nor feel the fitting sentiment which should be the perfect recompense of an artist who, symbolizing a lofty moral by a material trifle- converting what was earthly, to spiritual gold - had won the Beautiful into his handiwork." Tradução minha.
} 
acordo com o qual o autor “... nunca concebeu as mulheres como desnecessárias ou Evas ameaçadoras, mas, do contrário, como pilares emocionais, intelectuais e espirituais dos homens". 10 A representação positiva de Annie pelo narrador é realçada em: “... pois se algum espírito humano poderia ter reverenciado o processo tão sagrado a seus olhos, ele deveria ser o de uma mulher”. ${ }^{11}$

A visão puritana da mulher também é combatida em "A imagem de madeira de Drowne". ${ }^{12}$ Outra característica que liga esse conto ao "Artista do Belo" é o fato de o mesmo também lidar com o processo criativo. No entanto, ele distinguese do último em dois aspectos essenciais. Primeiramente, o criador em "Artista do Belo" não é um inventor e sim um artista. Além disso, a criação não é uma borboleta, mas um ser humano.

Drowne é um habilidoso entalhador em madeira que se especializara em fazer figuras de proa para navios. Antes de receber a encomenda de decorar o brigue do Capitão Hunnewell, seus trabalhos são descritos como sem vida, destituídos "daquela qualidade profunda, seja de alma ou de intelecto, que dá vida ao que é inerte e calor ao que é frio, e a qual, estivesse ela presente, teria impregnado de alma a imagem de madeira de Drowne". ${ }^{13}$ Copley, um amigo e admirador, assim reafirma a descrição do narrador: “... pois um toque a mais, faria dessa figura do General Wolfe, por exemplo, uma criatura humana, viva e inteligente". 14 Porém, quando Drowne começa a trabalhar na figura do Capitão, este toque parece emergir do bloco de carvalho e Copley é o primeiro a notar a transformação: "Eis aqui o toque divino, o toque doador da vida!"15

Um puritano ortodoxo consideraria uma blasfêmia o comentário de Copley, uma vez que ele atribui qualidade divina ao artista e à obra de arte. Por outro lado, tanto o narrador quanto o próprio Copley ignoram a visão puritana do orgulho e

\footnotetext{
10 1993. "Hawthorne never viewed women as unimportant of as threatening Eves, but, rather, as men's vital emotional, intellectual, and spiritual cohorts." Tradução minha.

${ }^{11}$ HAWTHORNE, 1982, p. 918: “[...] for if any human spirit could have sufficiently reverenced the process so sacred in his eyes, it must have been a woman's." Tradução minha.

${ }^{12}$ HAWTHORNE, 1982, p. 932-945.

${ }^{13}$ HAWTHORNE, 1964, p. 138.

${ }^{14}$ HAWTHORNE, 1964, p. 138.

${ }^{15}$ HAWTHORNE, 1964, p. 138.
} 
mostram-se em sintonia com a os ideais transcendentalistas com relação à criação, de acordo com os quais, "a referência de toda produção finalmente a um poder aborígine explica os traços comuns a todas as obras de arte maiores - que elas são universalmente inteligíveis; que elas restauram-nos os estados de mente mais simples; e que são religiosas." 16

Ao término da imagem, a figura de uma mulher emerge do bloco de carvalho. Essa figura feminina incomoda os puritanos de Nova Inglaterra por sua qualidade urbana e independente. A descrição inicial do narrador sugere que ela seria perversa, já que ela carrega "estranhas flores do Éden em sua cabeça". ${ }^{17}$ Contudo, o narrador é explicitamente crítico da obtusidade puritana ao descrever os detalhes do traje da mulher, "Foram... postos ali com tanto gosto quanto o poderia revelar uma mulher bonita, coisa da sua elegância, e a ninguém teriam chocado, exceto a uma pessoa estragada mercê de regras artísticas". ${ }^{18}$

A inicial reverência da população diante da imagem logo dá lugar a medo e à crença de que a mulher seria a própria projeção do mal. Mais tarde, quando a imagem abandona o bloco de madeira e ganha vida, o próprio entalhador é visto como perverso. Finalmente, após o capitão partir com a dama de carvalho, Drowne volta a ser o entalhador mecânico de antes. O narrador sugere que a transformação tenha ocorrido devido à sua decepção com a resposta da sociedade a seu trabalho. De fato, seu relato final não deixa dúvida quanto à forte influência do transcendentalismo em Hawthorne.

Ao comparar o Drowne mecânico ao mais espiritual, ele comenta:

Todavia, quem pode duvidar que o estado mais alto que um espírito humano pode atingir em suas mais sublimes aspirações, não seja o seu estado mais verdadeiro e natural, e que Drowne foi mais consistente consigo mesmo quando elaborou a figura admirável da misteriosa mulher, do que ao perpetrar toda uma progênie de broncas imagens? ${ }^{19}$

\footnotetext{
${ }^{16}$ EMERSON, 1950, p. 250.

${ }^{17}$ HAWTHORNE, 1964, p. 939.

${ }^{18}$ HAWTHORNE, 1964, p. 939.

${ }^{19}$ HAWTHORNE, 1964, p. 148.
} 
Assim, o narrador justifica a ambição de Drowne em criar vida através da arte e reage contra o puritanismo ao realçar a espontaneidade humana. Novamente, Hawthorne demonstra sua consonância com os ideais transcendentalistas do "selfreliance" e da "over-soul".

Os temas abordados por Hawthorne em "O Artista do Belo" e "A imagem de madeira de Drowne" são prova de seu interesse pela moral e religião. No entanto, as duas histórias mostram que Hawthorne não era um puritano tão conservador como defendem alguns críticos. De fato, ele buscou inspiração em Emerson para subverter princípios do puritanismo como o pecado do orgulho, a crença no mal inerente à raça humana e a representação da mulher baseada no Gênesis. Dessa forma, ele pôde manifestar sua desconfiança de uma sociedade puritana que se fecha ao novo e cultiva um "utilitarismo" cego, demonstrando sua fé na porção espiritual do homem e se colocando em defesa do idealista, seja ele o inventor ou o artista.

\section{Referências Bibliográficas}

ELLIS, Barbara. "Some Observations about Hawthorne's women”. WILLA II: 1318. Disponível em: <http://scholar.lib. vt.edu/ejournals/old-WILLA/fall93/kellis.htm,1 1993>

EMERSON, Ralph Waldo. Essays: First and Second Series. London: Oxford UP, 1950.

HAWTHORNE, Nathaniel. Hawthorne: Tales and Sketches. New York: Library Classics, 1982.

HAWTHORNE, Nathaniel. Histórias de Nathaniel Hawthorne. Trad. De Olívia Krahenbuh. São Paulo: Editora Cultrix, 1964.

MILLS, Barris. "Hawthorne and Puritanism." The New England Quarterly 21 (1948): 78-102. Disponível em: $\quad$ http://links.jstor.org/sici? sici=00284866\%28194803\%2921\%3A1\%3C78\%3AH AP\%3E2. 0.CO\%3B2-D

O’TOOLE, Heather. “The Blackness of men's souls:Why Nathaniel Hawthorne could not embrace Transcendentalism." Disponível em: http://www.bridgewater.edu/philo/philo96/otoole. html 
WARD, A. W. et al. "I 7. Transcendental Doctrines in Hawthorne: Self-Reliance; Compensation; Circles." The Cambridge History of English and American Literature. New York: Putnam's, 1907-21; New York: Bartleby.com, 2000. Disponível em: (www.bartleby.com/cambridge/). 